\title{
BMJ Open ProANP plasma measurement predicts all-cause mortality in acutely hospitalised patients: a cohort study
}

\author{
Bo K Lauridsen, ${ }^{1}$ Kasper Iversen, ${ }^{2}$ Ingrid Hunter, ${ }^{1}$ Morten Bay, ${ }^{3}$ Vibeke Kirk, ${ }^{4}$ \\ Olav W Nielsen, ${ }^{5}$ Henrik Nielsen, ${ }^{5}$ Søren Boesgaard, ${ }^{2}$ Lars Køber, ${ }^{2}$ Jens \\ $P$ Goetze $^{1}$
}

To cite: Lauridsen BK, Iversen K, Hunter I, et al. ProANP plasma measurement predicts all-cause mortality in acutely hospitalised patients: a cohort study. BMJ Open 2013;3:e003288.

doi:10.1136/bmjopen-2013003288

- Prepublication history and additional material for this paper is available online. To view these files please visit the journal online (http://dx.doi.org/10.1136/ bmjopen-2013-003288).

Received 23 May 2013 Revised 3 October 2013 Accepted 9 October 2013

CrossMark

For numbered affiliations see end of article.

Correspondence to Dr Jens P Goetze; JPG@ dadlnet.dk

\section{ABSTRACT}

Importance: The association of natriuretic peptide measurement with all-cause mortality in a broad selection of acutely admitted patients has not yet been examined.

Objective: To test the risk association between pro-atrial natriuretic peptide (ANP) and short-term and long-term mortality and its predictive value in acutely hospitalised patients and compare this to N-terminal B-type natriuretic peptide (NT-proBNP).

Design, setting and patients: Participants were selected from the Copenhagen Hospital Heart Failure Study $(\mathrm{n}=3644)$. Medical history, satisfactory echocardiography and blood samples were available on 2193 participants in 1998-1999 where NT-proBNP was measured. Vital status after discharge was obtained from national central data registers. A total of 1337 participants with eligible blood samples were selected in 2010-2011 for proANP measurement. Among these, 1255 (94\%) were acutely hospitalised in 1998-1999.

Main outcome measure(s): 1-year and long-term mortality.

Results: Median follow-up period was 11.5 years. At the end of follow-up, 926 patients had died, 239 during the first year. ProANP quartiles to 2-4 (median proANP levels $594 \mathrm{pmol} / \mathrm{L}, 990 \mathrm{pmol} / \mathrm{L}$ and $2052 \mathrm{pmol} /$ $\mathrm{L}$, respectively) associated with a stepwise increase in risk of 1-year and long-term mortality compared to the first quartile $(336 \mathrm{pmol} / \mathrm{L})$ in multivariable adjusted Cox proportional regression models (HR $1.5395 \% \mathrm{Cl} 1.30$ to 1.81 and HR $1.2695 \% \mathrm{Cl} 1.17$ to 1.36 , respectively). An addition of NT-proBNP attenuated proANP's association with mortality in the models (HR $1.2495 \% \mathrm{Cl} 1.01$ to 1.53 and $1.1495 \% \mathrm{Cl} 1.03$ to 1.26 , respectively). The increased risk was observed in participants with the highest proANP levels (fourth quartile). Similar results were observed in subgroups of participants with no evidence of cardiovascular disease (CVD). ProANP in quartiles improved discrimination when added to traditional risk factors in prediction models for 1-year (integrated discrimination improvement (IDI) $0.14195 \% \mathrm{Cl} 0.085$ to 0.197 ; C-index $0.75395 \% \mathrm{Cl} 0.724$ to 0.783 , P for improvement 0.003) and long-term mortality (IDI $0.05395 \% \mathrm{Cl} 0.032$ to 0.074 ; C-index $0.73695 \% \mathrm{Cl}$ 0.720 to 0.752 , $P$ for improvement $<0.001$ ) with similar results in subgroups. Discrimination was best

\section{Strengths and limitation of this study}

- Well characterised cohort with long follow-up and well-defined endpoint (mortality). Robust assay for proANP measurement.

- Lack of plasma on subset of cohort, however this subgroup did not differ in survival and baseline values.

in a combined model with proANP as well as NTproBNP included.

Conclusions and relevance: High plasma proANP concentrations are associated with and predict shortterm and long-term all-cause mortality in acutely hospitalised patients irrespective of CVD status at admission.

\section{INTRODUCTION}

Atrial natriuretic peptide (ANP) and B-type natriuretic peptide (BNP) have important physiological roles in fluid homeostasis and cardiac pathology, including myocardial ischaemia and left ventricular dysfunction. ${ }^{1}{ }^{2}$ BNP and the N-terminal precursor fragment (NT-proBNP) have been regarded as the biomarkers of choice when obtaining diagnostic and prognostic information in patients with heart failure. Recent development of assays measuring proANP-derived peptides suggests comparable performance with proBNP-derived peptides in heart failure populations. $^{3-6}$ Studies have also assessed a possible connection between natriuretic peptide concentrations and the risk of mortality in random populations, ${ }^{7-9}$ suggesting an association between plasma concentrations and mortality independently of other risk factors. However, reservations are generally noted due to short-term follow-up and small sample sizes. Accordingly, natriuretic peptide levels and risk of short-term and long-term 
mortality in a larger population of unselected, acutely hospitalised patients have yet to be examined.

In the present study we tested the hypothesis that the measurement of total proANP products in plasma may associate with and predict short-term and long-term allcause mortality in a large sample of unselected, acutely hospitalised patients irrespective of cardiovascular disease (CVD) status at study entry.

\section{METHODS}

\section{Design and study population}

The present study was based on plasma collected from participants in the Copenhagen Hospital Heart Failure Study. The primary study design has been published previously. ${ }^{10-12}$ Briefly stated, the cohort consisted of patients ( $>40$ years of age) admitted sequentially to Amager Hospital in Copenhagen. Enrolment occurred between 1 April 1998 and 31 March 1999. On admission, the medical history of all included participants was obtained together with a standard physical examination and a bedside echocardiography (Hewlett Packard Imagepoint, model M2410A; Andover, Massachusetts, USA). During the last 10 months of the study, $80 \%$ $(n=2230)$ of the included patients in that period had blood samples collected between $08: 00$ and 10:00. All data collection occurred within $24 \mathrm{~h}$ of admission. A total of 2193 of the 2230 patients had a satisfactory echocardiography.

A number of 1337 (61\%) of the 2193 participants with blood samples from 1998 to 1999 and echocardiographic examinations on record were eligible for proANP measurement in 2010-2011 (figure 1). Vital status or cause of death during follow-up was collected from national registers. Twenty-five (2\%) participants emigrated during the follow-up period and were censored at the time of emigration. Written consent was obtained at admission.

\section{Samples}

Blood samples were collected in EDTA-containing tubes and centrifuged at $4^{\circ} \mathrm{C}$. Plasma was stored at $-20^{\circ} \mathrm{C}$ and only thawed once during the initial investigations.

\section{ProANP measurement}

Plasma proANP was analysed in 2011 using an in-house method independent of changes in post-translational processing of the ANP precursor. ${ }^{13}$ This assay has previously been compared to an automated sandwich assay for midregional proANP with an excellent correlation. ${ }^{14}$ Notably, this assay measures an internal epitope in the $\mathrm{N}$-terminal proANP fragment that only is released after trypsin treatment of plasma; hence the assay is extremely robust in terms of degradation in frozen plasma. ${ }^{15}$

The coefficient of variation (inter-assay) was $11 \%$ at $1240 \mathrm{pmol} / \mathrm{L}$ and $6 \%$ at $2468 \mathrm{pmol} / \mathrm{L}$. Only $1337(61 \%)$ of the 2193 participants with blood samples and echocardiographic examinations on record were eligible for proANP measurement.

\section{Covariates}

A left ventricular ejection fraction (LVEF) $<50 \%$ was chosen as a cut-off point for defining left ventricular systolic dysfunction. NT-proBNP concentrations were measured at the time of inclusion using a two-step ELISA sandwich assay with streptavidin-coated microtitre plates. $^{16}$

\section{Statistics}

Plasma proANP concentrations were divided into quartiles or log-transformed because of skewed data distribution and presented as medians with IQRs. Descriptive data are presented as percentages or means with SDs. Test for differences were performed using Cochran-Armitage test for trend or Pearson's $\chi^{2}$ test for categorical data and analysis of variance or Mann-Whitney $U$ test for continuous data when appropriate. Comparisons were made between participants with and without proANP measurements on baseline values using Levene's test, and on mortality using survival curves and univariate Cox analysis.

Differences in survival were illustrated using Kaplan-Meier curves based on proANP quartiles and assessed using the log-rank test. Cox proportional regression analysis was used to evaluate the association between proANP concentrations and the risk of all-cause mortality, after testing the assumption of proportionality. Initially, a model was fitted using proANP (in quartiles) with age and sex as additional covariates. Subsequently a model consisting of well-known predictors of mortality (table 1) was fitted using backward elimination based on the Akaike information criterion (AIC) defined as $\mathrm{AIC}=$ $-2 \times$ maximum $\log$-likelihood(model) $+2 \times($ number of covariates). ${ }^{17}$ This balances between a model with high likelihood and a reasonable number of variables to achieve the lowest AIC possible. The final model included age, sex, alcohol, smoking, diabetes, history of congestive heart failure (CHF), history of pulmonary disease, history of liver disease, haemoglobin, ejection fraction below 50\% and New York Heart Association functional classification 3 or 4 . Missing data on covariates were imputed using age and sex as independent variables. ProANP (in quartiles) was then added and the association with mortality was assessed using HRs. Furthermore log-transformed values of proANP were used in all Cox models.

Prediction models for 1-year and long-term mortality were developed using the same covariates as in the multivariable Cox model and then adding proANP. Hence, models with traditional risk factors (model 1) were compared to models with traditional risk factors and proANP (model 2). Discrimination was evaluated by calculating the Integrated Discrimination Improvement (IDI).$^{18}$ The IDI can be regarded as the difference between improvement in average sensitivity and any potential increase in average 1-specificity when adding 


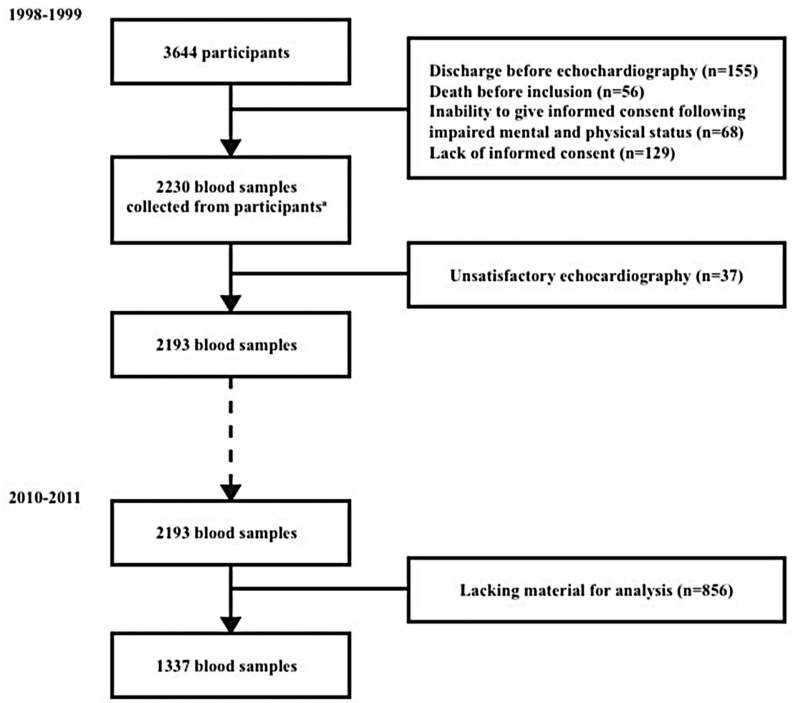

Figure 1 Selection of participants from the Copenhagen Hospital Heart Failure Study (1998-1999) for enrolment in the present study. ${ }^{\mathrm{a} B l o o d}$ samples collected from $80 \%$ of participants included during the past 10 months of the original study.

proANP to the prediction models. Furthermore, timedependent $\mathrm{C}$ statistics were calculated and differences in the $\mathrm{C}$ index were tested between models with and without proANP. ${ }^{19} 20$
Calibration was performed by testing the addition of proANP as an independent variable to the Cox models using the likelihood ratio test. Furthermore, all models were tested using Grønnesby and Borgan goodness-of-fit

Table 1 Baseline characteristics according to proANP quartiles

\begin{tabular}{|c|c|c|c|c|c|}
\hline & Quartile 1 & Quartile 2 & Quartile 3 & Quartile 4 & p Value \\
\hline $\mathrm{N}$ & 335 & 337 & 332 & 333 & \\
\hline proANP (pmol/L) (IQR) & $336(138)$ & $594(161)$ & $990(258)$ & 2052 (1068) & $<0.001$ \\
\hline 1-year mortality (\%) & $25(7.5)$ & $33(9.8)$ & 57 (17.2) & $124(37.2)$ & $<0.001$ \\
\hline Long-term mortality (\%) & $147(44.8)$ & $213(64.2)$ & 254 (78.4) & $312(95.1)$ & $<0.001$ \\
\hline Age (SD) & 58.5 (12.2) & $67.7(12.6)$ & 75.7 (12.3) & $80.3(9.5)$ & $<0.001$ \\
\hline Male sex (\%) & $172(51.3)$ & 131 (38.9) & $108(32.5)$ & $130(39.0)$ & $<0.001$ \\
\hline Smoking (\%) & 257 (76.7) & $251(74.5)$ & $226(68.3)$ & 229 (69.6) & 0.012 \\
\hline Alcohol (\%) & $60(18.0)$ & $43(12.8)$ & $29(8.8)$ & $19(5.8)$ & $<0.001$ \\
\hline \multicolumn{6}{|l|}{ Medical history of } \\
\hline Diabetes (\%) & $35(10.5)$ & $27(8.0)$ & $47(14.2)$ & $34(10.2)$ & 0.464 \\
\hline Hypertension (\%) & $84(25.1)$ & 77 (22.9) & $91(27.5)$ & $102(30.9)$ & 0.041 \\
\hline Liver disease (\%) & $9(2.7)$ & $11(3.3)$ & $9(2.7)$ & $11(3.3)$ & 0.739 \\
\hline Pulmonary disease (\%) & 60 (17.9) & $71(21.1)$ & $62(18.7)$ & $63(19.1)$ & 0.90 \\
\hline Ml (\%) & $17(5.1)$ & $27(8.0)$ & 35 (10.6) & $54(16.4)$ & $<0.001$ \\
\hline $\mathrm{CHF}(\%)$ & $7(2.1)$ & $23(6.8)$ & $43(13.0)$ & $90(27.3)$ & $<0.001$ \\
\hline $\mathrm{AP}(\%)$ & $36(10.8)$ & $68(20.2)$ & $88(26.6)$ & 95 (28.8) & $<0.001$ \\
\hline Valve disease (\%) & $3(0.9)$ & $7(2.1)$ & $9(2.7)$ & $15(4.6)$ & 0.003 \\
\hline \multicolumn{6}{|l|}{ Findings } \\
\hline \multicolumn{6}{|l|}{ NYHA class } \\
\hline $3(\%)$ & $3(0.9)$ & $13(3.9)$ & $24(7.3)$ & $58(18.0)$ & $<0.001$ \\
\hline $4(\%)$ & $0(0.0)$ & $2(0.6)$ & $0(0.0)$ & $5(1.5)$ & 0.025 \\
\hline eGFR (SD) & $102.5(30.4)$ & $90.6(30.9)$ & $78.5(26.7)$ & $63.1(27.5)$ & $<0.001$ \\
\hline $\mathrm{Hgb}(\mathrm{SD})$ & $8.5(1.1)$ & $8.2(1.2)$ & $8.0(1.2)$ & $7.8(1.3)$ & $<0.001$ \\
\hline LVEF<50 (\%) & $32(9.6)$ & $42(12.5)$ & $62(18.7)$ & $114(34.2)$ & $<0.001$ \\
\hline NT-proBNP (pmol/L) (IQR) & $24(32)$ & $60(80)$ & $147.5(160)$ & $477(740)$ & $<0.001$ \\
\hline
\end{tabular}

Values are mean $\pm S D$, median with IQR or $n$ with per cent. Differences between quartiles are tested using Cochran-Armitage test for trend or analysis of variance when appropriate.

$\mathrm{AP}$, angina pectoris; CHF, congestive heart failure; eGFR, estimated glomerual filtration rate; Hgb, haemoglobin; LVEF, left ventricular ejection fraction; MI, myocardial infarction; NYHA class, New York Heart Association functional classification. 
(GOF) test. ${ }^{21}$ Finally, internal validation was performed by bootstrapping the $\mathrm{C}$ statistics (resampling with 200 repetitions) to assess the degree of overfitting.

To further test the strength of proANP as an independent predictor of mortality in participants without cardiac impairment, all analyses were repeated using the same model; but excluding participants with evidence of CVD, defined as prior history of CHF, myocardial infarction, angina pectoris, valve disease, with $\mathrm{LVEF}<50 \%$ and/or New York Heart Association functional classification (NYHA class) 3 and 4 at admission.

NT-proBNP concentrations measured in 1998-1999 were used in the Cox models as well as the prediction models (model 3) as a quasi-internal validation of the endpoints in the population (with proANP measurements) and for direct comparison against proANP in the Cox and predictive models. Calibration was achieved in the same manner as proANP. Furthermore, model performances were tested after the addition of both proANP and NT-proBNP (model 4) to the multivariable predictive models and addition of proANP to predictive models with NT-proBNP included.

Statistical analyses were performed using SPSS V.16.0 (SPSS Inc, Chicago, Illinois, USA) and STATA V.12 (SataCorp LP, College Station, Texas, USA). A two-sided $p$ value $<0.05$ was considered statistically significant.

\section{RESULTS}

\section{Clinical characteristics}

No differences were noted between participants with and without proANP measurement on baseline values or short-term and long-term mortality (all $\mathrm{p}>0.05$; data not shown). All baseline characteristics of the participants are listed in table 1 . Mean age at admission was 70.5 years (SD 14.3 years), $796(59.5 \%)$ of participants were women. In total $1255(94 \%)$ participants were acutely hospitalised, while the remaining were admitted electively. The median proANP concentration was $780 \mathrm{pmol} / \mathrm{L}$ (IQR $912 \mathrm{pmol} / \mathrm{L}$ ). Median follow-up was 11.5 years (range 11.0-11.9 years). Follow-up was accomplished on 1337 (100\%) participants after 1 year and on $1337(100 \%)$ at the end of the study period. A total of $239(17.9 \%)$ participants died within the first year and $926(69.3 \%)$ during the entire follow-up period. In total $617(46.1 \%)$ participants had a history of CVD, 105 $(7.9 \%)$ were NYHA class 3 or 4 and $250(18.7 \%)$ had a LVEF $<50 \%$ recorded at entry.

\section{ProANP and survival}

Kaplan-Meier curves displayed stepwise significant differences in survival between the quartiles of proANP within the whole study population, with the highest survival seen among participants in the lowest quartile (figure 2, left panel; log-rank test $\mathrm{p}<0.001)$. Similar results were observed in the subgroup of participants, with no evidence of CVD (figure 2, right panel; log-rank test $\mathrm{p}<0.001)$.
ProANP association with mortality

ProANP quartiles 2, 3 and 4 displayed a stepwise increase in risk of 1-year mortality compared to the first quartile in the Cox proportional regression models (table 2; trend: age and sex+proANP: HR $1.6195 \%$ CI 1.38 to 1.87 ; $<<0.001$; multivariable+proANP: HR 1.53 $95 \%$ CI 1.30 to $1.81 ; \mathrm{p}<0.001)$. This stepwise association was still significant, but more modest when regarding long-term mortality (table 2; trend: age and sex +proANP: HR $1.3595 \%$ CI 1.26 to 1.45 ; $\mathrm{p}<0.001$; multivariable+proANP: $\mathrm{HR} \quad 1.26 \quad 95 \%$ CI 1.17 to 1.36 ; $\mathrm{p}<0.001)$.

Similar results were observed in subgroups of participants with no evidence of CVD (table 3). Results for proANP were attenuated when proANP as well as NT-proBNP were included in the models but remained significant on the trend (highest $\mathrm{p}=0.047$ ).

In most of the Cox regression models, the trend seemed to be carried primarily by the fourth quartile of proANP, which associated significantly with mortality (compared with the first quartile) in all models except in association with 1-year mortality in multivariable models with NT-proBNP included (tables 2 and 3; lowest $\mathrm{p}=0.083$ ). The log-transformed values of proANP and NT-proBNP also associated with short-term and longterm mortality (HRs for $1 \mathrm{log}$ unit change are seen in tables 2 and 3). Log transformed proANP performed modestly better than $\log$ transformed NT-proBNP in most analysis but proANP was also slightly skewed after $\log$ transformation.

Full Cox models with proANP or NT-proBNP included, before selections, are located in the supplemental appendix (see online supplemental tables 1-4).

\section{ProANP as a predictor of mortality}

Addition of proANP to the multivariable models improved discrimination, resulting in an IDI of 0.141 (95\% CI 0.085 to 0.197 ) and 0.053 (95\% CI 0.032 to 0.074 ) for 1-year and long-term mortality, respectively (table 4, model 2; all $\mathrm{P}$ for improvement $<0.001$ ). The corresponding IDIs were of the same magnitude in subgroups of participants without the evidence of CVD (table 5, model 2; highest $\mathrm{P}$ for improvement 0.001 ).

Time dependent C-statistics for 1-year and long-term mortality increased to 0.753 (95\% CI 0.724 to 0.783 ) and 0.736 (95\% CI 0.720 to 0.752$)$, after adding proANP to the multivariable models (table 4, model 2; $\mathrm{P}$ for improvement 0.003 and $<0.001$, respectively). Subgroup analysis, excluding participants with evidence of CVD, yielded similar improvements in C-statistics for 1-year and long-term mortality (table 5, model 2; $\mathrm{P}$ for improvement 0.019 and 0.001 , respectively).

NT-proBNP performed similar to proANP in all prediction models (tables 4 and 5, model 3) except for 1-year mortality in participants without the evidence of CVD where proANP consistently performed better although the difference was modest (table 5). A combined model including proANP as well as NT-proBNP 

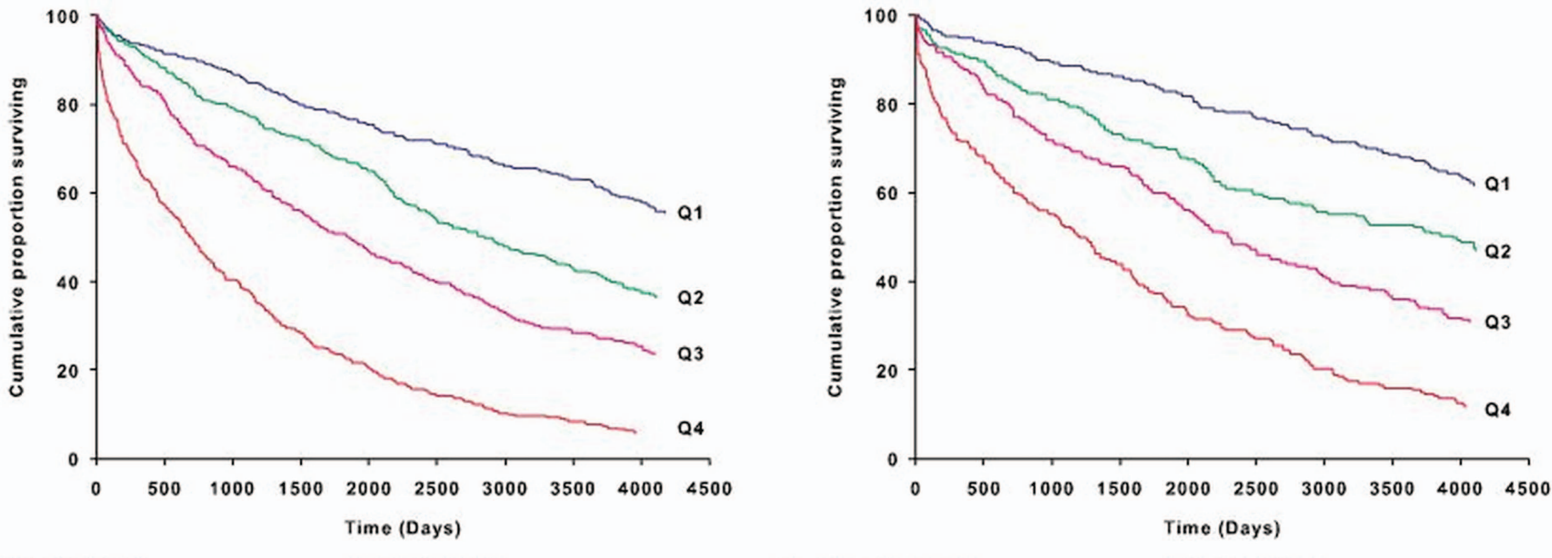

Quartiles of proANP

Numbers at risk

Quartiles of proANP

Numbers at risk

$\begin{array}{rrrrrrrrrr}\text { Q1 } & 335 & 305 & 290 & 267 & 252 & 237 & 221 & 211 & 194 \\ \text { Q2 } & 337 & 296 & 266 & 242 & 218 & 181 & 161 & 144 & 126 \\ \text { Q3 } & 332 & 267 & 218 & 185 & 155 & 132 & 109 & 94 & 84 \\ \text { Q4 } & 333 & 189 & 134 & 94 & 68 & 47 & 34 & 28 & 19\end{array}$

$\begin{array}{lrrrrrrrrr}\text { Q1 } & 211 & 197 & 188 & 181 & 172 & 161 & 152 & 144 & 134 \\ \text { Q2 } & 205 & 184 & 166 & 150 & 138 & 122 & 114 & 108 & 100 \\ \text { Q3 } & 207 & 171 & 147 & 135 & 115 & 97 & 84 & 74 & 65 \\ \text { Q4 } & 207 & 141 & 114 & 91 & 67 & 56 & 42 & 33 & 26\end{array}$

Figure 2 Unadjusted Kaplan-Meier curves for all-cause mortality (in days), by proANP quartiles. Left panel: Whole study population. Right panel: Participants with no evidence of cardiovascular disease (see text for details). All $\mathrm{P}<0.001$ for difference in survival tested by log-rank trend test.

Table 2 Cox proportional regression modelling of risk of 1-year and long-term all-cause mortalities

Age and sex +

HR $\quad 95 \% \mathrm{Cl}$ proANP/NT-proBNP
Multivariable + proANP/NT-proBNP*

HR $95 \%$ Cl p Value

Multivariable + proANP + NT-proBNP*

HR $95 \% \mathrm{Cl}$ p Value

1-year mortality

ProANP quartile (1 = reference)

1.01

0.59 to 1.72

0.967

0.185

3.11

0.85 to 2.37

4

1.90 to 5.08

Trend $\dagger$

$1.61 \quad 1.38$ to 1.87

$<0.001$

0.90

0.52 to 1.55

0.73 to 2.11

$2.63 \quad 1.56$ to 4.43

Pr. Log unit change

$2.16 \quad 1.77$ to 2.64

$<0.001$

1.53

1.30 to 1.81

2.05

1.64 to 2.56

$$
\text { e) }
$$

2

1.20

3

1.93

0.68 to 2.11

0.520

1.02

0.58 to 1.80

0.017

1.72

1.00 to 2.97

3.82

2.27 to 6.43

$<0.001$

3.15

1.83 to 5.42

Trendt

$1.68 \quad 1.45$ to 1.95

$<0.001$

1.60

1.36 to 1.88

$1.52 \quad 1.34$ to 1.71

Pr. Log unit change

1.52

1.37 to 1.69

$<0.001$

0.97 to 1.49

1.20

1.31

1.04 to 1.63

2.42

1.93 to 3.04

4 Trend†

$1.35 \quad 1.26$ to 1.45

Pr. Log unit change $\quad 1.70 \quad 1.53$ to 1.90

NT-ProBNP quartile (1 = reference)

\begin{tabular}{llllllllll}
2 & 1.15 & 0.92 to 1.42 & 0.219 & 1.02 & 0.82 to 1.27 & 0.848 & 1.03 & 0.81 to 1.30 & 0.829 \\
3 & 1.34 & 1.08 to 1.68 & 0.009 & 1.22 & 0.97 to 1.53 & 0.082 & 1.12 & 0.86 to 1.46 & 0.406 \\
4 & 2.36 & 1.89 to 2.95 & $0 .<001$ & 1.97 & 1.56 to 2.49 & $<0.001$ & 1.59 & 1.18 to 2.13 & 0.002 \\
Trend $\dagger$ & 1.35 & 1.26 to 1.45 & $<0.001$ & 1.28 & 1.19 to 1.38 & $<0.001$ & 1.18 & 1.07 to 1.30 & 0.001 \\
Pr. Log unit change & 1.31 & 1.24 to 1.38 & $<0.001$ & 1.26 & 1.19 to 1.34 & $<0.001$ & 1.16 & 1.07 to 1.26 & $<0.001$ \\
\hline
\end{tabular}

${ }^{*}$ Adjusted for age, sex, alcohol, smoking, diabetes, history of congestive heart failure, history of pulmonary disease, history of liver disease, haemoglobin, ejection fraction below $50 \%$ and New York Heart Association functional classification 3 or 4 .

†Trend across quartiles.

CVD, cardiovascular disease. 
Table 3 Cox proportional regression modelling of risk of 1-year and long-term all-cause mortalities in participants without evidence of cardiovascular disease (CVD)

\begin{tabular}{|c|c|c|c|c|c|c|c|c|c|}
\hline & \multicolumn{3}{|c|}{$\begin{array}{l}\text { Age and sex +proANPI } \\
\text { NT-proBNP }\end{array}$} & \multicolumn{3}{|c|}{$\begin{array}{l}\text { Multivariable +proANPI } \\
\text { NT-proBNP* }\end{array}$} & \multicolumn{3}{|c|}{$\begin{array}{l}\text { Multivariable +proANP + } \\
\text { NT-proBNP* }\end{array}$} \\
\hline & $\overline{\text { HR }}$ & $95 \% \mathrm{Cl}$ & p Value & $\overline{\text { HR }}$ & $95 \% \mathrm{Cl}$ & p Value & $\overline{\mathrm{HR}}$ & $95 \% \mathrm{Cl}$ & p Value \\
\hline \multicolumn{10}{|l|}{ 1-year mortality } \\
\hline \multicolumn{10}{|c|}{ ProANP quartile ( $1=$ reference) } \\
\hline 2 & 1.17 & 0.63 to 2.18 & 0.623 & 0.91 & 0.47 to 1.73 & 0.767 & 0.90 & 0.45 to 1.78 & 0.754 \\
\hline 3 & 1.13 & 0.58 to 2.20 & 0.720 & 0.86 & 0.43 to 1.72 & 0.676 & 0.78 & 0.35 to 1.74 & 0.545 \\
\hline 4 & 3.56 & 1.88 to 6.76 & $<0.001$ & 2.82 & 1.46 to 5.46 & 0.002 & 2.11 & 0.91 to 4.88 & 0.083 \\
\hline Trend† & 1.61 & 1.30 to 1.99 & $<0.001$ & 1.54 & 1.23 to 1.92 & $<0.001$ & 1.37 & 1.04 to 1.82 & 0.027 \\
\hline Pr. Log unit change & 2.19 & 1.62 to 2.96 & $<0.001$ & 2.04 & 1.48 to 2.82 & $<0.001$ & 1.53 & 0.99 to 2.38 & 0.058 \\
\hline \multicolumn{10}{|c|}{ NT-ProBNP quartile (1 = reference) } \\
\hline 2 & 1.20 & 0.63 to 2.29 & 0.579 & 0.91 & 0.48 to 1.76 & 0.789 & 1.02 & 0.50 to 2.06 & 0.955 \\
\hline 3 & 1.58 & 0.82 to 3.04 & 0.173 & 1.20 & 0.62 to 2.34 & 0.586 & 1.08 & 0.49 to 2.41 & 0.847 \\
\hline 4 & 3.83 & 2.00 to 7.34 & $<0.001$ & 2.63 & 1.35 to 5.12 & 0.004 & 1.70 & 0.72 to 4.04 & 0.228 \\
\hline Trend† & 1.65 & 1.33 to 2.03 & $<0.001$ & 1.48 & 1.19 to 1.85 & $<0.001$ & 1.24 & 0.93 to 1.64 & 0.140 \\
\hline Pr. Log unit change & 1.59 & 1.34 to 1.89 & $<0.001$ & 1.49 & 1.25 to 1.79 & $<0.001$ & 1.27 & 0.99 to 1.62 & 0.060 \\
\hline \multicolumn{10}{|l|}{ Long-term mortality } \\
\hline \multicolumn{10}{|c|}{ ProANP quartile $(1=$ reference) } \\
\hline 2 & 1.33 & 1.03 to 1.72 & 0.029 & 1.22 & 0.94 to 1.58 & 0.142 & 1.22 & 0.92 to 1.61 & 0.171 \\
\hline 3 & 1.27 & 0.96 to 1.68 & 0.091 & 1.09 & 0.82 to 1.45 & 0.544 & 1.02 & 0.72 to 1.42 & 0.931 \\
\hline 4 & 2.47 & 1.82 to 3.33 & $<0.001$ & 2.10 & 1.54 to 2.85 & $<0.001$ & 1.62 & 1.10 to 2.39 & 0.016 \\
\hline Trend† & 1.30 & 1.18 to 1.44 & $<0.001$ & 1.23 & 1.11 to 1.37 & $<0.001$ & 1.14 & 1.00 to 1.30 & 0.047 \\
\hline Pr. Log unit change & 1.56 & 1.33 to 1.82 & & 1.46 & 1.24 to 1.71 & $<0.001$ & 1.16 & 0.93 to 1.44 & 0.18 \\
\hline \multicolumn{10}{|c|}{ NT-ProBNP quartile (1 = reference) } \\
\hline 2 & 1.12 & 0.86 to 1.45 & 0.391 & 0.96 & 0.74 to 1.25 & 0.770 & 0.94 & 0.70 to 1.26 & 0.678 \\
\hline 3 & 1.30 & 0.98 to 1.71 & 0.065 & 1.14 & 0.86 to 1.51 & 0.374 & 1.04 & 0.74 to 1.45 & 0.830 \\
\hline 4 & 2.36 & 1.75 to 3.17 & $<0.001$ & 2.01 & 1.49 to 2.73 & $<0.001$ & 1.63 & 1.11 to 2.39 & 0.013 \\
\hline Trend† & 1.32 & 1.19 to 1.45 & $<0.001$ & 1.26 & 1.14 to 1.39 & $<0.001$ & 1.18 & 1.03 to 1.34 & 0.014 \\
\hline Pr. Log unit change & 1.30 & 1.20 to 1.42 & $<0.001$ & 1.27 & 1.16 to 1.38 & $<0.001$ & 1.20 & 1.07 to 1.35 & 0.002 \\
\hline
\end{tabular}

resulted in the best discrimination (tables 4 and 5 , model 4) measured as significant improvement of IDI's and C-index compared to the multivariable model on 1-year and long-term mortality including subgroups (highest $\mathrm{P}$ for improvement 0.022). Models with proANP and NT-proBNP provided modestly better discrimination compared to models with NT-proBNP included, for long-term mortality $(\mathrm{p}=0.015$ and $\mathrm{p}=0.069$ for improvement in IDI and C-index, respectively) and in subgroups without evidence of CVD (tables 4 and 5).

\section{Calibration}

The likelihood improved significantly with addition of proANP to all models including multivariable models with NT-proBNP (highest $\mathrm{p}=0.042$ ). No models violated the Grønnesby and Borgan test (all p >0.05), indicating adequate GOF. Bootstrap estimates revealed a low degree of overfitting in all models.

\section{DISCUSSION}

This study demonstrates that proANP plasma concentrations independently associate with all-cause mortality in an unselected population of acutely hospitalised patients. Furthermore, this association persisted in participants with seemingly normal cardiac function. To our knowledge, this is the first study to show such a correlation. Including the proANP measurement to wellestablished risk factors of short-term and long-term mortality also improved discrimination, which underscores the general usefulness of this marker in the prognostic evaluation of the acutely hospitalised patient.

Several other studies have evaluated the association between natriuretic peptide concentrations and death. Most of these have mainly focused on populations with a history of cardiovascular disease. ${ }^{7}{ }^{22-24}$ Others include healthy populations in which the clinical validity of measuring natriuretic peptides regarding predictability of cardiovascular or all-cause mortality is debatable. ${ }^{25-27}$ In general, the present population has a higher frequency and severity of acute and chronic illnesses compared to outpatients and healthy volunteers. This population thus closely resembles what the clinician encounters in the hospital.

As the majority $(94 \%)$ of participants was acutely admitted to the hospital, we looked at other studies where the populations had similar backgrounds. Several studies have investigated the diagnostic properties of 
Table 4 Comparison between risk prediction models of risk of 1-year and long-term all-cause mortality

\begin{tabular}{|c|c|c|c|c|c|}
\hline & Model 1 & Model 2 & Model 3 & Model 4 & \\
\hline \multicolumn{6}{|l|}{ 1-year mortality } \\
\hline \multicolumn{6}{|l|}{ Discrimination } \\
\hline IDI & & $0.141(0.085-0.197)^{\star}$ & $0.176(0.118-0.234)^{\star}$ & $0.201(0.137-0.266)^{\star}$ & $0.025(-0.002-0.052) \dagger$ \\
\hline Relative IDI & & $0.183^{*}$ & $0.229^{*}$ & $0.262^{*}$ & $0.026 \dagger$ \\
\hline $\mathrm{p}$ Value & & $<0.001^{*}$ & $0 .<001^{*}$ & $0 .<001^{*}$ & $0.070 \dagger$ \\
\hline C-index & $0.731(0.701-0.760)$ & $0.753(0.724-0.783)$ & $0.754(0.725-0.783)$ & $0.759(0.730-0.788)$ & \\
\hline p-difference & & $0.003^{*}$ & $0.005^{\star}$ & $0.001^{*}$ & $0.141 \dagger$ \\
\hline \multicolumn{6}{|c|}{ Long-term mortality } \\
\hline \multicolumn{6}{|l|}{ Discrimination } \\
\hline IDI & & $0.053(0.032-0.074)^{\star}$ & $0.054(0.031-0.077)^{\star}$ & $0.070(0.045-0.094)^{\star}$ & $0.015(0.0029-0.027) \dagger$ \\
\hline Relative IDI & & $0.044^{*}$ & $0.046^{*}$ & ${ }^{*} 0.059^{*}$ & $0.012 \dagger$ \\
\hline $\mathrm{p}$ Value & & $<0.001^{*}$ & $<0.001^{*}$ & $<0.001^{*}$ & $0.015 \dagger$ \\
\hline C-index & $0.725(0.709-0.741)$ & $0.736(0.720-0.752)$ & $0.737(0.721-0.753)$ & $0.739(0.724-0.755)$ & \\
\hline p-difference & & $<0.001^{*}$ & $<0.001^{*}$ & $<0.001^{\star}$ & $0.069 \dagger$ \\
\hline
\end{tabular}

Model 1: Adjusted for age, sex, alcohol, smoking, diabetes, history of congestive heart failure, history of pulmonary disease, history of liver disease, haemoglobin, ejection fraction below $50 \%$ and New York Heart Association functional classification 3 or 4 . Model 2: model $1+$ quartiles of proANP. Model 3: model 1+ quartiles of NT-proBNP. Model 4: model 1+ quartiles of proANP + quartiles of NT-proBNP.

*Versus model 1 .

†Versus model 3. 


\begin{tabular}{|c|c|c|c|c|c|}
\hline & Model 1 & Model 2 & Model 3 & Model 4 & \\
\hline \multicolumn{6}{|l|}{ 1-year mortality } \\
\hline \multicolumn{6}{|l|}{ Discrimination } \\
\hline IDI & & $0.185(0.086-0.284)^{*}$ & $0.118(0.039-0.197)^{\star}$ & $0.210(0.102-0.318)^{*}$ & $0.092(0.025-0.160) \dagger$ \\
\hline Relative IDI & & $0.192^{*}$ & $0.122^{*}$ & $0.218^{*}$ & $0.085 \dagger$ \\
\hline $\mathrm{p}$ Value & & $<0.001^{*}$ & $0.004^{*}$ & $<0.001^{*}$ & $0.007 \dagger$ \\
\hline C-index & $0.758(0.718-0.797)$ & $0.780(0.740-0.821)$ & $0.773(0.733-0.813)$ & $0.782(0.741-0.822)$ & \\
\hline p difference & & $0.019^{*}$ & $0.070^{*}$ & $0.022^{*}$ & $0.178 \dagger$ \\
\hline \multicolumn{6}{|c|}{ Long-term mortality } \\
\hline \multicolumn{6}{|l|}{ Discrimination } \\
\hline IDI & & $0.045(0.018-0.072)^{*}$ & $0.049(0.022-0.077)^{\star}$ & $0.072(0.039-0.105)^{\star}$ & $0.023(0.004-0.041) \dagger$ \\
\hline Relative IDI & & $0.039^{*}$ & $0.043^{*}$ & $0.062^{*}$ & $0.019 \dagger$ \\
\hline$p$ Value & & $0.001^{*}$ & $<0.001^{*}$ & $<0.001^{*}$ & $0.015 \dagger$ \\
\hline C-index & $0.736(0.715-0.757)$ & $0.747(0.726-0.768)$ & $0.744(0.723-0.765)$ & $0.748(0.727-0.769)$ & \\
\hline $\mathrm{p}$ difference & & $0.001^{*}$ & $0.013^{*}$ & $0.001^{*}$ & $0.015 \dagger$ \\
\hline
\end{tabular}

Model 1: Adjusted for age, sex, alcohol, smoking, diabetes, history of pulmonary disease, history of liver disease, haemoglobin. Model 2:

model $1+$ quartiles of proANP. Model 3: model 1+ quartiles of NT-proBNP. Model 4: model 1+ quartiles of proANP + quartiles of NT-proBNP. *Versus model 1.

†Versus model 3.

natriuretic peptide measurement in patients with acute dyspnoea as the primary symptom. ${ }^{28-30}$ In the ProBNP Investigation of Dyspnoea in the Emergency Department (PRIDE) trial, NT-proBNP measurement was shown to have valuable diagnostic applications as a rule-out marker of heart failure in a cohort of 599 patients presenting with acute shortness of breath. ${ }^{31} \mathrm{~A}$ follow-up study using the PRIDE cohort found NT-proBNP to be a strong predictor of 1-year mortality in a multivariate analysis (HR $2.8895 \%$ CI 1.64 to 5.06; $\mathrm{p}<0.001) .{ }^{32}$ The conclusion was identical in a follow-up article evaluating multiple markers. ${ }^{33}$

Even though our study on proANP measurement showed equal prognostic properties, caution must be made when making direct comparisons. The PRIDE cohort consisted of selective patients (with dyspnoea) whereas our cohort consisted of a broad selection of patient categories (see online supplemental table 5). Of the 599 patients in the PRIDE cohort presenting with acute dyspnoea, 209 (36\%) were diagnosed with acute heart failure, and patients with acute severe ischaemia were excluded. In our population, $250(18.7 \%)$ had a LVEF $<50 \%$ with even fewer admitted with symptoms of heart failure. These circumstances further enhance the general findings in our study.

Another large group of participants in the present study were orthopaedic patients $(16.1 \%)$. Chong et $a l^{34}$ measured preoperative and postoperative proBNP concentrations in 89 elderly patients (mean age 70.9 years $\mathrm{SD} \pm 9.6$ ) scheduled for emergency orthopaedic surgery. Their study revealed that preoperative and postoperative proBNP measurements were the strongest significant predictors of 1-year and 2-year mortality in a multivariable analysis (OR 3.3 95\% CI 1.2 to 9.0 and OR $3.495 \%$ CI 1.1 to 11.0 , respectively), but not when cardiovascular events before discharge were included in the model. The latter remained the single significant predictor of mortality (OR $4.795 \%$ CI 1.5 to 14.9). Nonetheless, the conclusion was that proBNP measurements are useful in identifying surgical patients at risk of cardiac events and later all-cause mortality. Since trauma patients were almost non-existent among participants in the present study, it is likely that similar circumstances partly contributed to the results in our study population.

The biological explanations for the observed association between increased proANP concentrations and mortality in the present study are numerous. Natriuretic peptides are well-established predictors of cardiovascular mortality and morbidity. Nevertheless, other diverse conditions can lead to elevated peptide concentrations, such as cancer, renal failure and pulmonary embolism. ${ }^{35}$

Since the (older) 1998-1999 NT-proBNP measurement technique is now discarded, a comparison of performance between these biomarkers in the context of the present study must be made with caution, and more studies are needed. However, it can be noted that proANP consistently seemed to associate strongest with long-term mortality patients seemingly free of cardiac impairment. This could be consistent with a more cardiac-oriented sensitivity of NT-proBNP.

\section{Study strengths and limitations}

Major strengths of the present study include a large, broad cohort with a well-defined endpoint (all-cause mortality) and a long follow-up period (up to 11.5 years). The latter, achievable by using more robust analysis techniques, opens up the possibility of further studies involving similar cohorts with long follow-up. A major limitation in our study is the lack of spare plasma from a large part of the original population which increases the risk of sample bias. However, the baseline values and survival in participants with proANP samples were similar to those without samples.

We also lacked detailed information on additional predictors of mortality such as body mass index, cholesterol levels, which could also be used in a clinical setting. 
Furthermore, the lack of repeated measurements prohibited us from using time-dependent covariates. However, this could be a minor issue, since part of the pathophysiology behind the elevated natriuretic peptides inevitably leads to death.

\section{CONCLUSION}

In conclusion, our study provides evidence that high plasma proANP concentrations are associated with and predict short-term and long-term all-cause mortality in acutely hospitalised patients irrespective of CVD status at admission. This could potentially lead to improved risk of stratification using proANP or a combination of proANP and NT-proBNP, which would lend vital support in the evaluation of the acutely hospitalised patient.

\section{Author affiliations}

${ }^{1}$ Department of Clinical Biochemistry, Rigshospitalet, Copenhagen, Denmark

${ }^{2}$ Department of Cardiology, Rigshospitalet, Copenhagen, Denmark

${ }^{3}$ Department of Cardiology, Frederiksberg Hospital, Copenhagen, Denmark

${ }^{4}$ Department of Oncology, Herlev Hospital, Herlev, Denmark

${ }^{5}$ Department of Cardiology, Bispebjerg Hospital, Copenhagen, Denmark

Acknowledgements The authors would like to thank Dijana Terzic for expert laboratory assistance with the proANP analyses.

Contributors BKL conducted primary data analysis and wrote the first draft. $\mathrm{KI}$ participated in data analysis and reviewed the manuscript. IH developed the proANP analysis method and reviewed the manuscript. MB and VK participated in study setup and data collection on participants and reviewed the manuscript. OWN, HN and SB participated in study setup and reviewed the manuscript. LK reviewed the manuscript. JPG developed the proANP analysis, measured the samples and helped with drafting of the manuscript.

Funding Rigshospitalets Forskningsråd (JPG).

Competing interests None.

Provenance and peer review Not commissioned; externally peer reviewed.

Data sharing statement No additional data are available.

Open Access This is an Open Access article distributed in accordance with the Creative Commons Attribution Non Commercial (CC BY-NC 3.0) license, which permits others to distribute, remix, adapt, build upon this work noncommercially, and license their derivative works on different terms, provided the original work is properly cited and the use is non-commercial. See: http:// creativecommons.org/licenses/by-nc/3.0/

\section{REFERENCES}

1. De Lemos JA, Morrow DA, Bentley JH, et al. The prognostic value of B-type natriuretic peptide in patients with acute coronary syndromes. N Engl J Med 2001;345:1014-21.

2. Richards AM, Nicholls MG, Espiner EA, et al. B-type natriuretic peptides and ejection fraction for prognosis after myocardial infarction. Circulation 2003:107:2786-92.

3. Schnabel RB, Schulz A, Messow CM, et al. Multiple marker approach to risk stratification in patients with stable coronary artery disease. Eur Heart J 2010;31:3024-31.

4. Moertl D, Berger R, Struck J, et al. Comparison of midregional pro-atrial and B-type natriuretic peptides in chronic heart failure: influencing factors, detection of left ventricular systolic dysfunction, and prediction of death. J Am Coll Cardiol 2009; 53:1783-90.

5. Khan SQ, Dhillon O, Kelly D, et al. Plasma N-terminal B-type natriuretic peptide as an indicator of long-term survival after acute myocardial infarction: comparison with plasma midregional pro-atrial natriuretic peptide: the LAMP (Leicester Acute Myocardial Infarction Peptide) study. J Am Coll Cardiol 2008;51:1857-64.
6. Van Hateren KJ, Alkhalaf A, Kleefstra N, et al. Comparison of midregional pro-A-type natriuretic peptide and the $\mathrm{N}$-terminal pro-B-type natriuretic peptide for predicting mortality and cardiovascular events. Clin Chem 2012;58:293-7.

7. Wang TJ, Larson MG, Levy D, et al. Plasma natriuretic peptide levels and the risk of cardiovascular events and death. N Engl J Med 2004;350:655-63

8. Wallén $\mathrm{T}$, Landahl $\mathrm{S}$, Hedner $\mathrm{T}$, et al. Brain natriuretic peptide in an elderly population. $J$ Intern Med 1997;242:307-11.

9. Christ $\mathrm{M}$, Thuerlimann $\mathrm{A}$, Laule $\mathrm{K}$, et al. Long-term prognostic value of B-type natriuretic peptide in cardiac and non-cardiac causes of acute dyspnoea. Eur J Clin Invest 2007;37:834-41.

10. Bay M, Kirk V, Parner J, et al. NT-proBNP: a new diagnostic screening tool to differentiate between patients with normal and reduced left ventricular systolic function. Heart 2003; 89:150-4.

11. Kirk V, Bay M, Parner J, et al. N-terminal proBNP and mortality in hospitalised patients with heart failure and preserved vs. reduced systolic function: data from the prospective Copenhagen Hospital Heart Failure Study (CHHF). Eur J Heart Fail 2004;6:335-41.

12. Wendelboe Nielsen O, Kirk V, Bay M, et al. Value of N-terminal pro brain natriuretic peptide in the elderly: data from the prospective Copenhagen Hospital Heart Failure study (CHHF). Eur J Heart Fail 2004;6:275-9.

13. Hunter I, Rehfeld JF, Goetze JP. Measurement of the total proANP product in mammals by processing independent analysis. $J$ Immunol Methods 2011;370:104-10.

14. Hunter I, Alehagen U, Dahlström U, et al. Peptide measurement in plasma suggests covalent modification. Clin Chem 2011;57:1327-30.

15. Goetze JP, Hunter I, Lippert SK, et al. Processing-independent analysis of peptide hormones and prohormones in plasma. Front Biosci 2012;17:1804-15.

16. Karl J, Borgya A, Gallusser A, et al. Development of a novel, $\mathrm{N}$-terminal-proBNP (NT-proBNP) assay with a low detection limit. Scand J Clin Lab Invest Suppl 1999;230:177-81.

17. Akaike $\mathrm{H}$. A new look at the statistical model identification. IEEE Trans Automatic Control 1974;19:716-23.

18. Pencina MJ, D'Agostino RB, Vasan RS. Evaluating the added predictive ability of a new marker: from area under the ROC curve to reclassification and beyond. Stat Med 2008;27:157-72.

19. Harrell FE Jr, Califf RM, Pryor DB, et al. Evaluating the yield of medical tests. JAMA 1982;247:2543-6.

20. Newson RB. Comparing the predictive powers of survival models using Harrell's C or Somers' D. Stata J 2010;10:339-58.

21. May S, Hosmer DW. A simplified method of calculating an overall goodness-of-fit test for the Cox proportional hazards model. Lifetime Data Anal 1998;4:109-20.

22. Latini R, Masson S, Anand I, et al. The comparative prognostic value of plasma neurohormones at baseline in patients with heart failure enrolled in Val-HeFT. Eur Heart $J$ 2004;25:292-9.

23. Alehagen U, Dahlström U, Rehfeld JF, et al. Association of copeptin and N-terminal proBNP concentrations with risk of cardiovascular death in older patients with symptoms of heart failure. JAMA 2011;305:2088-95.

24. Alehagen U, Dahlström U, Rehfeld JF, et al. Prognostic assessment of elderly patients with symptoms of heart failure by combining high-sensitivity troponin $\mathrm{T}$ and $\mathrm{N}$-terminal pro-B-type natriuretic peptide measurements. Clin Chem 2010;56:1718-24.

25. Kistorp C, Raymond I, Pedersen F, et al. N-terminal pro-brain natriuretic peptide, C-reactive protein, and urinary albumin levels as predictors of mortality and cardiovascular events in older adults. JAMA 2005;293:1609-16.

26. McKie PM, Cataliotti A, Lahr BD, et al. The prognostic value of $\mathrm{N}$-terminal pro-B-type natriuretic peptide for death and cardiovascular events in healthy normal and stage $A / B$ heart failure subjects. J Am Coll Cardiol 2010;55:2140-7.

27. Linssen GC, Bakker SJ, Voors AA, et al. N-terminal pro-B-type natriuretic peptide is an independent predictor of cardiovascular morbidity and mortality in the general population. Eur Heart $J$ 2010;31:120-7.

28. Gruson D, Rousseau MF, Ahn S, et al. Accuracy of $\mathrm{N}$-terminal-pro-atrial natriuretic peptide in patients admitted to emergency department. Scand J Clin Lab Invest 2008; 68:410-14.

29. Davis M, Espiner E, Richards G, et al. Plasma brain natriuretic peptide in assessment of acute dyspnoea. Lancet 1994;343:440-4.

30. McCullough PA, Nowak RM, McCord J. B-Type natriuretic peptide and clinical judgment in emergency diagnosis of heart failure: analysis from Breathing Not Properly (BNP) Multinational Study. Circulation 2002;106:416-22. 
31. Januzzi JL Jr, Camargo CA, Anwaruddin S, et al. The N-terminal Pro-BNP investigation of dyspnea in the emergency department (PRIDE) study. Am J Cardiol 2005;95:948-54.

32. Januzzi JL Jr, Sakhuja R, O'donoghue M, et al. Utility of amino-terminal pro-brain natriuretic peptide testing for prediction of 1 -year mortality in patients with dyspnea treated in the emergency department. Arch Intern Med 2006;166:315-20.

33. Rehman SU, Martinez-Rumayor A, Mueller T, et al. Independent and incremental prognostic value of multimarker testing in acute dyspnea: results from the ProBNP Investigation of Dyspnea in the Emergency Department (PRIDE) study. Clin Chim Acta 2008;392:41-5.

34. Chong CP, Ryan JE, Van Gaal WJ, et al. Usefulness of N-terminal pro-brain natriuretic peptide to predict postoperative cardiac complications and long-term mortality after emergency lower limb orthopedic surgery. Am J Cardiol 2010;106:865-72.

35. Rehman SU, Januzzi JL Jr. Natriuretic peptide testing in clinical medicine. Cardiol Rev 2008;16:240-9. 